\title{
An Airborne Electronic Equipment Life Prediction Method Based on Normal Distribution Fitting
}

\author{
Wengao Qian, Hongyan Ma, and Chen Xiao
}

\begin{abstract}
According to the current status that the Civil Aviation Industry lack of effective method for airborne electronic equipment life prediction. Based on studying characteristic parameters of the airborne electronic equipment lifecycle, this paper analyzes some real service data of airborne electronic equipment, and then use airborne electronic equipment life prediction method which based on normal distribution fitting, study the life distribution of series components with the same part number, and gives the confidence interval of the overall mean and variance in the 0.9 confidence level.
\end{abstract}

Index Terms-Airborne electronic equipment, life prediction, normal distribution fitting, confidence interval

\section{INTRODUCTION}

Airborne electronic equipment is repairable product, It can be used in the cycle of "use-repair-use", and most of the components are no depletion period. Most of the failures in the service life are randomly. If the airborne electronic equipment faults, it will cause great economic loss and casualty, even a major accident. Life is an important indicator of the airborne equipment running condition, and the current civil aviation industry lack of an effective method for airborne electronic equipment life prediction.

Broadly speaking, according to the theory of reliability engineering, life is one of the reliability parameters of the product. It involves the safe, reliable, economic, and other factors. Due to the longer life of airborne electronic equipment, and most of the products does not exist a significant depletion period, life prediction of no suitable can be monitored depletion parameters and performance degradation parameters, while the airborne electronic products is repairable products, does not give the total life, but only gives the mean time between failures(MTBF) generally. Therefore, this paper analyzes some real service data of airborne electronic equipment, then use airborne electronic equipment life prediction method which based on normal distribution fitting.

\section{The AIRborne EleCtronic EQUiPMENT CHARACTERISTIC PARAMETERS IN THE LIFE CYCLE}

This paper focuses on the airborne electronic equipment

Manuscript received October 16, 2012; revised November 22, 2012.

Wengao Qian and Chen Xiao are with the College of Aviation Automation Engineering, Civil Aviation University of China, China (e-mail:wgqian_yjs08@cauc. edu.cn, cxiao_yjs10@cauc.edu.cn).

Hongyan $\mathrm{Ma}$ is with the Basic Experimental Center, Civil Aviation University of China, China (e-mail: hyma_yjs09@cauc.edu.cn). economic life, which reflected in the process of rational management and routine maintenance after the aircraft put into use. The life prediction is mainly based on the statistical reliability data in the day-to-day operations of the airline.

\section{A. MTBF of the Airborne Electronic Equipment}

Assume that the airborne electronic equipment set is recorded as $(\mathrm{e} 1, \mathrm{e} 2, \ldots \ldots \mathrm{eN})$. In the cycle of "use-repair-use", each installation time of ei is recorded as a set $\left(t(i)_{00}, t(i)_{01}, \cdots \cdots, t(i)_{0 n}\right)$. The failure time corresponding to each installation is recorded as $\left(t(i)_{10}, t(i)_{11}, \cdots \cdots, t(i)_{1 n}\right)$. Which $t_{00}$ is the time of the new equipment put into use, $t_{10}$ is the time of the new equipment first failure, $t_{1 n}$ is the time of ei reached the end of the economic life. [1]

The MTBF of the airborne electronic equipment ei:

$$
m t b f(i)=\frac{\sum_{j=0}^{n}\left(t(i)_{1 j}-t(i)_{0 j}\right)}{n+1}
$$

The MTBF of the airborne electronic equipment set:

$$
M T B F=\frac{\sum_{i=1}^{N} m t b f(i)}{N}
$$

where $N$ is the scale of the sample space.

\section{B. TBF (time between failures) of the Airborne Electronic} Equipment

The MTBF of the airborne electronic equipment and the equipment set reflects the overall reliability of the airborne electronic equipment set and the same kind of airborne electronic equipment in a given period. However, the MTBF will submerge the characteristics of each time between failure, not completely reflect the characteristics of the airborne electronic equipment life cycle. Therefore, the $\mathrm{j}$-th TBF in life cycle of ei is recorded as:

$$
\operatorname{tbf}(i)_{j}=t(i)_{1 j}-t(i)_{0 j}
$$

\section{The AIrborne ElECTRONIC EQUIPMENT LIFE PREDICTION METHOD BASED ON NORMAL DISTRIBUTION FITTING}

The major forecasting processes are given as follows: [2]

\section{A. The Determination of Characteristic Parameters}

The characteristic parameters in the airborne electronic equipment life cycle includes the time between failures, 
MTBF, the number of failures, the cumulative service time, the first time between failures. We choose the time between failures as the characteristic parameters for the study.

\section{B. Data Preprocessing}

Preprocess electronic equipment real service data which the Airlines statistics, the time between failures was spun off as a characteristic parameter for the further data analysis. According to the repair date and the return date in the airborne electronic equipment life cycle, through the repair time minus the last return with the same subject, we can obtain the time between failures in days. Consider the average day use time of domestic airlines Boeing series aircraft is 10.04 hours, this paper use day use time as 10 to convert the time between failures into hours.

\section{Power Transform and Normal Fitting Goodness Test}

Draw the frequency distribution histogram of the time between failures of the series components with the same part number, determine the distribution initially. If the result of normal fitting goodness test is not ideal, power transform for the original series. By taking different power values, we can obtain different transform series, normal fitting goodness test for the transformed series, to identify the power value corresponding to the optimal normal fitting.

\section{The Confidence Interval Estimation of General Mean and Variance}

According to the Normal distribution and its interval estimation theory, estimate the confidence interval estimation of general mean and variance for the transformed series. Here, the confidence level is 0.9 .

\section{E. Series Inverse Transformation and the Original Series Confidence Interval Estimation}

Inverse transform confidence interval of the transformed series, obtain the overall mean and variance estimation of the original series.

\section{The Calculation Example}

\section{A. Data Preprocessing}

The aircraft fault is divided into three categories, namely Category A (affect flight safety), B class (affect the mission completed), class $\mathrm{C}$ (can be excluded after the completion of the mission). In the aircraft line maintenance, the three types of failure came in different important levels. If the aircraft faults, you need to consult the MEL and treat it differently. MEL provides a specific period of repair for the aircraft failure release, such as the Chinese civil aviation regulations that the longest retention period is 24 hours of the failure of the Class A and B class failure 72 hours, C class fault 240 hours.

There are some real service data of the IRU series equipment of an airline, the time from 199.01.01 to 2004.12.31. List the real service data with the part number HG1050AD10 (TABLE I).
TABLE I: THE SERVICE PROCESS DATA OF HG1050AD10 SERIES EQUIPMENT

\begin{tabular}{|c|c|c|c|c|c|}
\hline Series No. & Failure date & Return date & \begin{tabular}{|c|} 
Series \\
No.
\end{tabular} & $\begin{array}{c}\text { Failure } \\
\text { date }\end{array}$ & $\begin{array}{c}\text { Return } \\
\text { date }\end{array}$ \\
\hline 3384 & $2001-10-25$ & $2001-12-13$ & 2438 & $2000-4-5$ & $2000-5-10$ \\
\hline 3384 & & 2003-11-19 & 2438 & $2000-8-22$ & 2000-10-17 \\
\hline 3384 & $1999-9-28$ & 1999-11-19 & 2438 & $\begin{array}{c}2001-12-1 \\
7\end{array}$ & $2002-2-11$ \\
\hline 3390 & 2001-4-17 & 2001-6-11 & 4806 & $\begin{array}{c}2001-11-1 \\
9\end{array}$ & $2002-1-14$ \\
\hline 3390 & $2003-7-21$ & 2003-9-17 & 4806 & 2003-1-17 & $2003-3-26$ \\
\hline 3390 & $1999-11-30$ & & 4806 & 2004-2-11 & $2004-5-25$ \\
\hline 4021 & 2004-3-15 & 2004-4-19 & 4806 & $2004-6-22$ & 2004-9-27 \\
\hline 4021 & $2001-8-8$ & $2001-9-20$ & 6486 & $2001-8-24$ & 2001-10-16 \\
\hline 4021 & $2003-3-25$ & $2003-5-13$ & 6486 & 2004-6-14 & $2004-7-20$ \\
\hline 4021 & $2004-9-27$ & $x$ & 6650 & 2001-1-11 & $2001-2-27$ \\
\hline 4273 & 2004-1-19 & 2004-3-11 & 6650 & $2001-9-29$ & 2001-11-9 \\
\hline 4273 & $004-9-6$ & $x$ & Jan-18 & $2001-8-31$ & 2001-11-14 \\
\hline 4525 & 2001-11-9 & $2001-12-27$ & Jan-18 & $2003-3-5$ & 2003-4-21 \\
\hline 4525 & 2002-10-30 & $2003-1-29$ & Jan-93 & $2000-1-26$ & $2000-3-20$ \\
\hline 6135 & 2004-3-19 & $2004-4-26$ & Jan-93 & $\begin{array}{c}2000-10-3 \\
0\end{array}$ & $2000-12-12$ \\
\hline 6135 & $2003-1-20$ & 2003-3-11 & 6391 & $\begin{array}{c}1999-10-1 \\
8\end{array}$ & 1999-11-18 \\
\hline 93110112 & 2003-11-17 & $2003-12-29$ & 6391 & $2001-4-9$ & $2001-5-31$ \\
\hline 93110112 & 2004-6-14 & $2004-7-20$ & 6391 & $2004-6-22$ & $x$ \\
\hline 94010189 & $2000-7-5$ & $2000-8-14$ & Jan-56 & $2000-9-22$ & $2000-11-1$ \\
\hline 94010189 & $2003-8-27$ & $2003-11-3$ & Jan-56 & $2001-8-31$ & $2001-11-30$ \\
\hline 94080410 & $2002-7-22$ & $2002-9-4$ & Jan-56 & $2002-4-22$ & $2002-6-3$ \\
\hline 94080410 & $2004-2-5$ & $2004-5-17$ & Jan-56 & $2003-12-2$ & 2004-1-21 \\
\hline Jan-93 & $1999-9-9$ & 1999-11-4 & Jan-93 & 2001-9-19 & $2001-12-13$ \\
\hline
\end{tabular}

The " $x$ " in the return date column of table1 represent the IRU reached the end of the economic life due to high maintenance costs of the failure. Because of the failure is not for maintenance, repair level " $x$ " indicates that no maintenance level. By repair time minus the last return time with the same part number and serial number, we can obtain the time between failures in days. Through the unit conversion, obtain the time between failures of series IRU unit with part number HG1050AD10 (TABLE II ).

TABLE II: THE TIME BETWEEN FAILURES OF SERIES IRU UNIT WITH PART NUMBER HG1050AD10 (UNIT: HOUR)

\begin{tabular}{cc|cc}
\hline \hline Series No. & TBF & Series No. & TBF \\
\hline 2438 & 1040 & 4806 & 3680 \\
2438 & 4260 & 4806 & 3220 \\
3384 & 7060 & 4806 & 280 \\
3384 & 6540 & 6391 & 5080 \\
3390 & 4470 & 6391 & 11180 \\
3390 & 7700 & 6486 & 9720 \\
4021 & 5510 & 6135 & 3740 \\
4021 & 3070 & 4525 & 3070 \\
4021 & 1610 & 6650 & 2140 \\
4273 & 1790 & Jan-18 & 4760 \\
Jan-56 & 3030 & Jan-93 & 2240 \\
Jan-56 & 1430 & Jan-93 & 2810 \\
Jan-56 & 5470 & Jan-93 & 1680 \\
93110112 & 1680 & 94010189 & 11080 \\
94080410 & 5190 & & \\
\hline \hline
\end{tabular}




\section{B. Data Transformation and Normal Distribution Fit test}

Record the time between failures of HG1050AD10 series unit as $X_{10}=(1040,4260,7060,6540,4470,7700,5510$, $3070,1610,1790,3070,3680,3220,280,3740,5080,11180,972$ $0,2140,4760,3030,1430,5470,830,2240,2810,1680,11080,5$ 190).

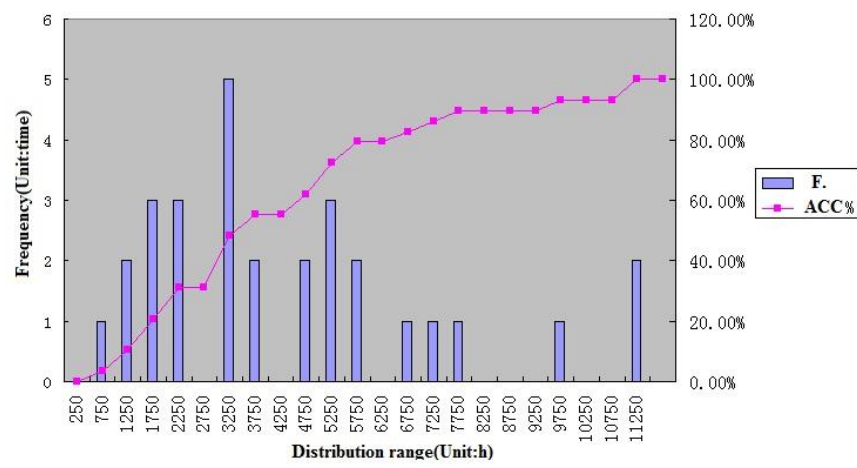

Fig. 1. The time between failures of the HG1050AD10 series

Through the number sequence power transformation, obtain the new sequence. Normal distribution fit test the new sequence by the MATLAB function jbtest. The complete form of the function jbtest is [H, P, JBSTAT, CV, $=$ jbtest $(X$, alpha), where, $P$ is the probability value of accepting the hypothesis, the closer to 0 , you can refuse the normal distribution null hypothesis; JBSTAT is the value of the test statistic, CV is the critical value to reject the null hypothesis; $H$ is the test result, if $H=0$, it may be considered that $X$ follow a normal distribution; if $H=1$, we can reject the null. The power exponent is different; the transformation series is also different. The value of the different series normal distribution fit test is recorded in TABLE III.

TABLE III: THE VALUE OF SERIES NORMAL DISTRIBUTION FIT TEST

\begin{tabular}{ccccc}
\hline Power exponent of X10 & $\mathrm{H}$ & $\mathrm{P}$ & JBSTAT & $\mathrm{CV}$ \\
\hline 0.20 & 0 & 0.7091 & 0.6874 & 5.9915 \\
\hline 0.25 & 0 & 0.8030 & 0.4387 & 5.9915 \\
\hline 0.29 & 0 & 0.8448 & 0.3373 & 5.9915 \\
\hline 0.30 & 0 & 0.8509 & 0.3228 & 5.9915 \\
\hline 0.31 & 0 & 0.8555 & 0.3122 & 5.9915 \\
\hline 0.32 & 0 & 0.8585 & 0.3051 & 5.9915 \\
\hline 0.33 & 0 & 0.8601 & 0.3014 & 5.9915 \\
\hline 0.34 & 0 & 0.8604 & 0.3008 & 5.9915 \\
\hline 0.35 & 0 & 0.8600 & 0.3016 & 5.9915 \\
\hline 0.40 & 0 & 0.8376 & 0.3545 & 5.9915 \\
\hline 0.45 & 0 & 0.7947 & 0.4596 & 5.9915 \\
\hline 0.50 & 0 & 0.7379 & 0.6079 & 5.9915 \\
\hline 0.60 & 0 & 0.6028 & 1.0124 & 5.9915 \\
\hline 0.70 & 0 & 0.4607 & 1.5500 & 5.9915 \\
\hline 0.80 & 0 & 0.3286 & 2.2257 & 5.9915 \\
\hline & & & & \\
\hline \hline
\end{tabular}

With the power exponent value of $X_{10}$ as the horizontal axis, the corresponding value of $P$ as the vertical axis, plot Fig. 2.

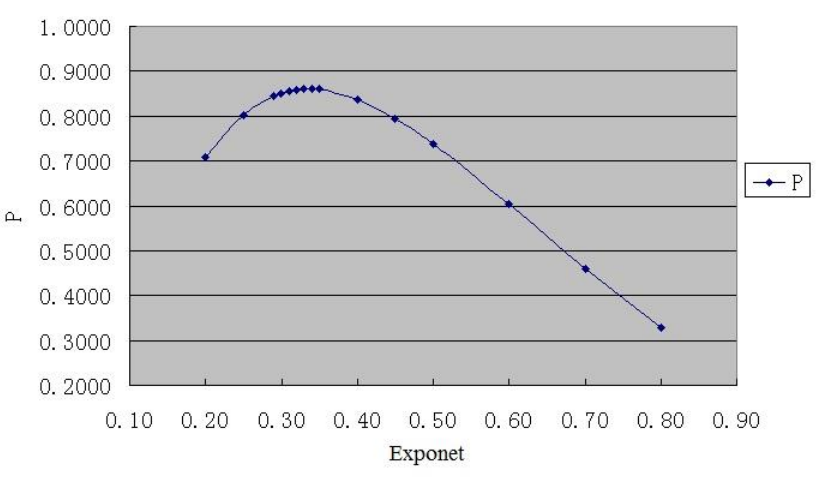

Fig. 2. The distribution map of $P$.

In Table III, $H$ is 0 , it can be considered that $X$ X10 obeys normal distribution; The $P$ increases first and then slowly decline in the interval 0.2 to 0.8 ; the maximum value of $P$ is 0.8604 with power exponent 0.34. At this point, the transformed series normal distribution fittimg goodness test best. The transformed series with power exponent 0.34 is recorded as $X_{10}{ }^{0.34}=(10.6119,17.1395,20.3514,19.8288$, $17.4223,20.9608,18.7065,15.3330,12.3118,12.7635$, $15.3330,16.3075,15.5837,6.7926,16.3975,18.1967$, $23.7942,22.6885,13.5625,17.7986,15.2648,11.8254$, $18.6602,9.8285,13.7748,14.8785,12.4912,23.7216$, 18.3298). Series $X_{10}{ }^{0.34} \sim N(\mu, \delta 2)$, the distribution histogram of $X_{10}{ }^{0.34}$ as shown in Fig. 3.

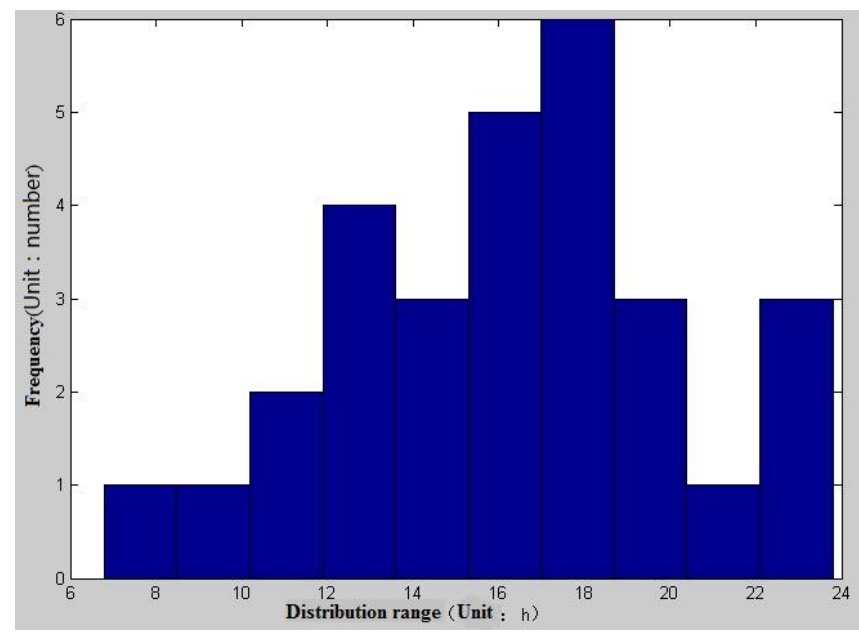

Fig. 3. The distribution histogram of series $\mathrm{X}_{10}{ }^{0.34}$.

\section{The HG1050AD10 Interval Estimate of the General} Mean-Variance

\section{1) The interval estimate of the general mean}

Electronic equipment failure is random, and there is no obvious recession. It is difficult to obtain general variance $\delta 2$ from the day-to-day maintenance data which the Airlines statistics. In the condition of $\delta 2$ unknown, the confidence interval of the mean $\mu$ with the confidence level $1-\alpha$ is recorded as: [3]

$$
\left(\bar{X}-\frac{S}{\sqrt{n}} t_{\alpha / 2}(n-1), \bar{X}+\frac{S}{\sqrt{n}} t_{\alpha / 2}(n-1)\right)
$$

where $\alpha=0.1$, through looking-up the table and calculating, the confidence interval of the mean $\mu$ of the series X100.34 with the confidence level 0.9 is $(14.9317,17.5275)$.

Through the confidence interval of X100.34 inverter heat 
transform, we can obtain the confidence interval (2839.6000, 4549.9000 ) of the mean $\mu$ of the original series.

2) The interval estimate of the general variance

In the condition of $\mu$ unknown, the confidence interval of the variance $\delta 2$ with the confidence level $1-\alpha$ is recorded as:

$$
\left(\frac{(n-1) S^{2}}{\chi_{\alpha / 2}^{2}(n-1)}, \frac{(n-1) S^{2}}{\chi_{1-\alpha / 2}^{2}(n-1)}\right)
$$

where $\alpha=0.1$, through looking-up the table and calculating, the confidence interval of the variance $\delta 2$ of the series $\mathrm{X} 100.34$ with the confidence level 0.9 is $(11.4356,27.9250)$.

Through the confidence interval of X100.34 inverter heat transform, we can obtain the confidence interval (1295. 8000,17903.0000) of the variance of the original series[4].

\section{CONCLUSION}

Due to the differences of application Environment, false alarms, and other factors, there is big difference between airborne electronic equipment actual life and design life. Based on this, this paper analyzes some real service data of airbor ne electronic equipment, then use airborne electronic equipment life prediction method which based on normal distribution fitting, study the life distribution of series components with the same part number, and gives the confidence interval of the general mean and variance in the 0.9 confidence level. Because of the limited data, the aircraft avionics life prediction method remains to be further validation of the large amounts of data.

\section{ACKNOWLEDGMENT}

First author would like to thank the Data Analysis Institute of Civil Aviation University of China (CAUC).

\section{REFERENCES}

[1] H. H. Smirnov, "The aircraft operational reliability and maintenance system," Beijing: First Institute of the Chinese People's Liberation Army Air Force, 1983, pp. 23-45.

[2] H. Ying, "Research on Civil Aviation Engine Fault Diagnosis and Life Predication Based on Intelligent Technologies," Ph.D. Nan Jing University of Aeronautics \& Astronautics, 2006.

[3] L. M. Yan, L. Feng, and S. Y. Xing, "Study of Confidence Interval Estimation Methods of Product Reliability Life Using Field Data," Acta Aeronautica et Astronautica Sinicn, pp. 77-82, May. 1995.

[4] X. R. Li and Y. Bar-Shalom, "Multiple-model estimation with variable structure-Part 1," IEEE Transactions on Automatic Control (S0018-9286), pp. 478-493, Nov.1996.

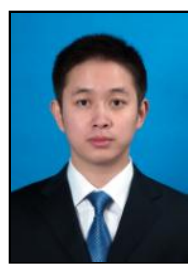

Wengao Qian received the Bachelor's degree in Electronic and Information Engineering from Nanjing University of Aeronautics and Astronautics, Nanjing, China in 2007 and the Master's degree in Control Theory and Control Engineering from Civil Aviation University of China, Tianjin, China in 2011. Currently he is with Civil Aviation University of China, Tianjin, China, where he is a teacher in the College of Aviation Automation Engineering. His research interests include data analysis and avionics maintenance.

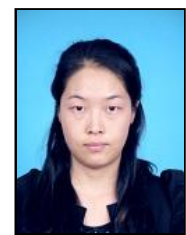

Hongyan Ma received the Bachelor's degree in Electronic and Information Engineering and Master's degree in Navigation, Guidance and Control from Civil Aviation University of China, Tianjin, China in 2009 and 2012. Currently she is with Civil Aviation University of China, Tianjin, China, where she is a teacher in the Basic Experimental Center. Her research interests include data analysis and avionics maintenance.

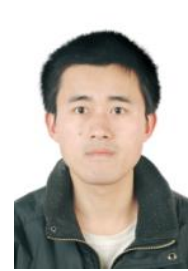

Chen Xiao received the Bachelor's degree in Electrical Engineering and Automation from Inner Mongolia Agricultural University, Inner Mongolia, China in 2009. $\mathrm{He}$ is currently working towards the Master's degree at Civil Aviation University of China, China. 